OPEN ACCESS

Edited by:

Steve Suib,

University of Connecticut,

United States

Reviewed by:

Balaraman Ekambaram National Chemical Laboratory (CSIR),

India

Liwu Zhang

Fudan University, China Guohong Wang,

Hubei Normal University, China

${ }^{*}$ Correspondence: Shinya Furukawa furukawa@cat.hokudai.ac.jp Takayuki Komatsu komatsu.t.ad@m.titech.ac.jp

Specialty section: This article was submitted to Catalysis and Photocatalysis,

a section of the journal

Frontiers in Chemistry

Received: 27 November 2018 Accepted: 25 February 2019

Published: 20 March 2019

Citation:

Furukawa S, Nishimura G, Takayama T and Komatsu T (2019)

Highly Active Ni- and Co-Based Bimetallic Catalysts for Hydrogen Production From Ammonia-Borane.

Front. Chem. 7:138.

doi: 10.3389/fchem.2019.00138

\section{Highly Active Ni- and Co-Based Bimetallic Catalysts for Hydrogen Production From Ammonia-Borane}

\author{
Shinya Furukawa ${ }^{1,2 *}$, Genki Nishimura ${ }^{3}$, Tomoaki Takayama ${ }^{3}$ and Takayuki Komatsu ${ }^{3 *}$ \\ ${ }^{1}$ Institute for Catalysis, Hokkaido University, Sapporo, Japan, ${ }^{2}$ Elements Strategy Initiative for Catalysts and Batteries, Kyoto \\ University, Kyoto, Japan, ${ }^{3}$ Department of Chemistry, School of Science, Tokyo Institute of Technology, Tokyo, Japan
}

Ammonia-borane is one of the most promising candidates for hydrogen carriers. A series of $\mathrm{Ni}$ - and Co-based bimetallic catalysts supported on $\mathrm{SiO}_{2}\left(\mathrm{Ni}-\mathrm{M} / \mathrm{SiO}_{2}\right.$ and $\left.\mathrm{Co}-\mathrm{M} / \mathrm{SiO}_{2} ; \mathrm{M}=\mathrm{Ga}, \mathrm{Ge}, \mathrm{Sn}, \mathrm{Zn}\right)$ was prepared and tested as catalysts for hydrogen production from ammonia-borane (AB) in water or methanol. $\mathrm{Ni}-\mathrm{Zn} / \mathrm{SiO}_{2}$ and $\mathrm{Co}-\mathrm{Ge} / \mathrm{SiO}_{2}$ exhibited catalytic activities much higher than those of monometallic $\mathrm{Ni} / \mathrm{SiO}_{2}$ and $\mathrm{Co} / \mathrm{SiO}_{2}$, respectively. $\mathrm{Ni}-\mathrm{Zn} / \mathrm{SiO}_{2}$ showed a high catalytic activity when water was used as a solvent, where the reaction was completed within $6 \mathrm{~min}$ at room temperature with a specific reaction rate of $4.3 \mathrm{ml} \mathrm{min}^{-1} \mathrm{mmol}_{-\mathrm{cat}^{-1}} \mathrm{mM}-\mathrm{AB}^{-1}$. To the best of our knowledge, this is the highest value among those reported using $3 \mathrm{~d}$ metal-based catalysts. $\mathrm{Co}-\mathrm{Ge} / \mathrm{SiO}_{2}$ afforded a five-fold higher reaction rate than that of the corresponding monometallic $\mathrm{Co} / \mathrm{SiO}_{2}$. XRD, TEM, and HAADF-STEM-EDS analyses revealed that $\mathrm{Ni}_{0.75} \mathrm{Zn}_{0.25}$ and $\mathrm{CO}_{0.8} \mathrm{Ge}_{0.2}$ solid-solution alloys were formed with high phase purities. An XPS study showed that Co atoms in $\mathrm{Co}_{0.8} \mathrm{Ge}_{0.2}$ were electron-enriched due to electron transfer from Ge to Co, which may be the origin of the improved catalytic activity.

Keywords: hydrogen production, ammonia borane, hydrolysis, alloy, catalyst

\section{INTRODUCTION}

Hydrogen has been considered as one of the best energy carrier alternatives to fossil fuels because of its high energy density, clean combustion product (only water), and environmental friendliness (Schlapbach and Züttel, 2011). Hydrogen is currently produced by steam reforming of methane contained in natural gas (Heinzel et al., 2002), which is not renewable and sustainable. Therefore, alternative methodologies such as photocatalytic (Moniz et al., 2015; Chen et al., 2017; Wang et al., 2017) and photoelectrochemical (Zhang et al., 2014; Zheng and Zhang, 2016; Han et al., 2017) water splitting have recently attracted increasing attention. On the other hand, storage, transport, and release of hydrogen are known as technological barriers to practical application in view of cost and safety (Züttel, 2003). Ammonia-borane $\left(\mathrm{H}_{3} \mathrm{~N} \cdot \mathrm{BH}_{3}\right.$, hereafter $\left.\mathrm{AB}\right)$ is one of the more promising candidates as a hydrogen carrier or source (Landge et al., 2018) owing to its high hydrogen content (19.6 wt\%), high thermal stability, and low toxicity (Marder, 2007). AB can release three equimolar amounts of hydrogen at ambient temperatures using an appropriate catalyst through solvolysis 
with protic solvents such as water and methanol. Using noble metals such as $\mathrm{Pt}, \mathrm{Rh}$, Ir enables the achievement of rapid hydrogen release typically within several minutes (Chandra and $\mathrm{Xu}, 2007$; Xu and Chandra, 2007). Recently, development of non-noble $3 \mathrm{~d}$ transition metal-based catalysts that are active for hydrogen production from $\mathrm{AB}$ has been increasingly focused (Xu and Chandra, 2006; Yan et al., 2008, 2009; Kalidindi et al., 2009; Metin et al., 2010; Patel et al., 2010; Ozay et al., 2011; Peng et al., 2015). To develop highly efficient catalytic systems using base metal elements, the catalytic activity of these metals should be greatly enhanced by appropriate catalyst design such as the modification of morphology, the addition of some cocatalysts, or the formation of alloy phases (Furukawa and Komatsu, 2017).

In this study, a series of $\mathrm{Ni}$ - and Co-based bimetallic catalysts was prepared $\left(\mathrm{Ni}-\mathrm{M} / \mathrm{SiO}_{2}\right.$ and $\mathrm{Co}-\mathrm{M} / \mathrm{SiO}_{2} ; \mathrm{M}=\mathrm{Ga}, \mathrm{Ge}, \mathrm{Sn}$, and $\mathrm{Zn}$ ) and tested as catalysts for hydrogen production from $\mathrm{AB}$ in water or methanol as a solvent. The observed catalytic performances were discussed in view of the reaction mechanism. Herein, we report a novel and highly efficient catalytic system for hydrogen production from $\mathrm{AB}$ using non-noble metal catalysts.

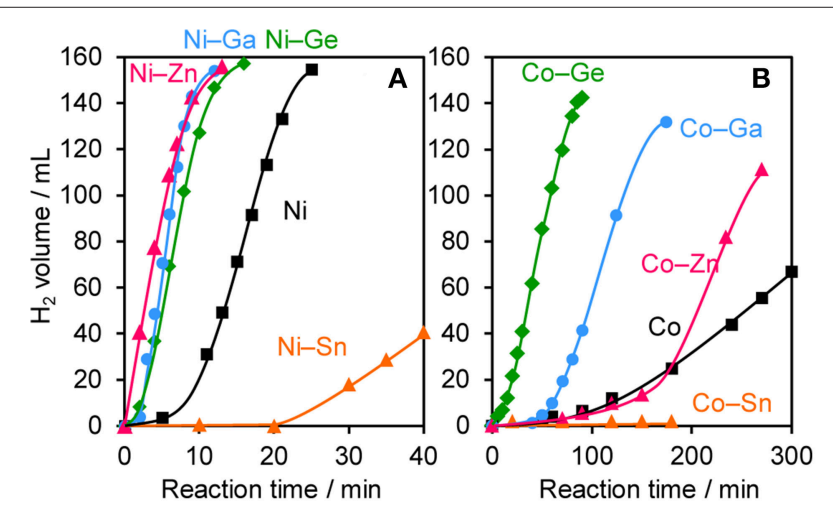

FIGURE 1 | Time course of $\mathrm{H}_{2}$ evolution during catalytic methanolysis of $A B$ using (A) Ni- and (B) Co-based catalysts.

\section{MATERIALS AND METHODS}

\section{Catalyst Preparation}

Monometallic $\mathrm{Ni}$ and Co catalysts were prepared by porefilling impregnation using silica as a support. Aqueous solutions of $\mathrm{Ni}\left(\mathrm{NO}_{3}\right)_{2} \cdot 6 \mathrm{H}_{2} \mathrm{O}$ (Wako, 99\%) or $\mathrm{Co}\left(\mathrm{NO}_{3}\right)_{2} \cdot 3 \mathrm{H}_{2} \mathrm{O}$ (Sigma Aldrich, 99\%) were added to dried silica gel (CARiACT G-6, Fuji Silysia, $S_{\mathrm{BET}}=470 \mathrm{~m}^{2} \mathrm{~g}^{-1}$ ) so that the solutions filled the silica pores. The mixtures were sealed overnight at room temperature and dried over a hot plate, followed by reduction under flowing $\mathrm{H}_{2}$ at $600^{\circ} \mathrm{C}$ for $1 \mathrm{~h}$. Silica-supported Ni- and Cobased catalysts $\left(\mathrm{Ni}-\mathrm{M} / \mathrm{SiO}_{2}\right.$ and $\mathrm{Co}-\mathrm{M} / \mathrm{SiO}_{2} ; \mathrm{M}=\mathrm{Ga}, \mathrm{Ge}, \mathrm{Sn}$, and $\mathrm{Zn}$ ) were prepared by pore-filling co-impregnation. Mixed aqueous solutions of $\mathrm{Ni}\left(\mathrm{NO}_{3}\right)_{2} \cdot 6 \mathrm{H}_{2} \mathrm{O}$ or $\mathrm{Co}\left(\mathrm{NO}_{3}\right)_{2} \cdot 3 \mathrm{H}_{2} \mathrm{O}$ and $\mathrm{a}$ second metal salt, $\mathrm{Ga}\left(\mathrm{NO}_{3}\right)_{3} \cdot \mathrm{nH}_{2} \mathrm{O}$ (Wako, 99.9\%), $\left(\mathrm{NH}_{4}\right)_{2} \mathrm{GeF}_{6}$ (Sigma Aldrich, 99.99\%), $\mathrm{SnCl}_{2}$ (Kanto, 97\%), and $\mathrm{Zn}\left(\mathrm{NO}_{3}\right)_{2}$. $6 \mathrm{H}_{2} \mathrm{O}$ (Kanto, 99\%) were used in a manner similar to that of the monometallic catalyst. The metal loading of $\mathrm{Ni}$ or $\mathrm{Co}$, the atomic ratio of $\mathrm{Ni} / \mathrm{M}$ or $\mathrm{Co} / \mathrm{M}$, and the reduction temperature during the catalyst preparation were set to $3 \mathrm{wt} \%, 3.0$, and $600^{\circ} \mathrm{C}$ except for $\mathrm{Ni}-\mathrm{Ge}$ and $\mathrm{Co}-\mathrm{Ge}$, which had a reduction temperature of $800^{\circ} \mathrm{C}$, and Co-Sn with an atomic ratio of 1.0.

\section{Characterizations}

The crystal structures of the catalysts were determined by powder X-ray diffraction (XRD) with a Rigaku RINT2400 diffractometer using a $\mathrm{Cu} \mathrm{K} \alpha \mathrm{X}$-ray source. Difference XRD patterns were obtained by subtracting the pattern for the $\mathrm{SiO}_{2}$ support from those of the supported catalysts. Transmission electron microscopy (TEM) was conducted using a JEOL JEM$2010 \mathrm{~F}$ microscope at an accelerating voltage of $200 \mathrm{kV}$. To prepare the TEM specimen, all samples were sonicated in tetrachloromethane and then dispersed on a $\mathrm{Cu}$ grid supported by an ultrathin carbon film. X-ray photoelectron spectra (XPS) of the bimetallic compounds were measured with an ULVAC PHI 5000 VersaProbe spectrometer. The catalyst was pressed into a pellet and placed into a quartz reactor, where it was reduced under flowing hydrogen $\left(60 \mathrm{ml} \mathrm{min}^{-1}\right)$ at $450^{\circ} \mathrm{C}$ for $0.5 \mathrm{~h}$ prior to the measurement. The sample was put into a transfer vessel in a
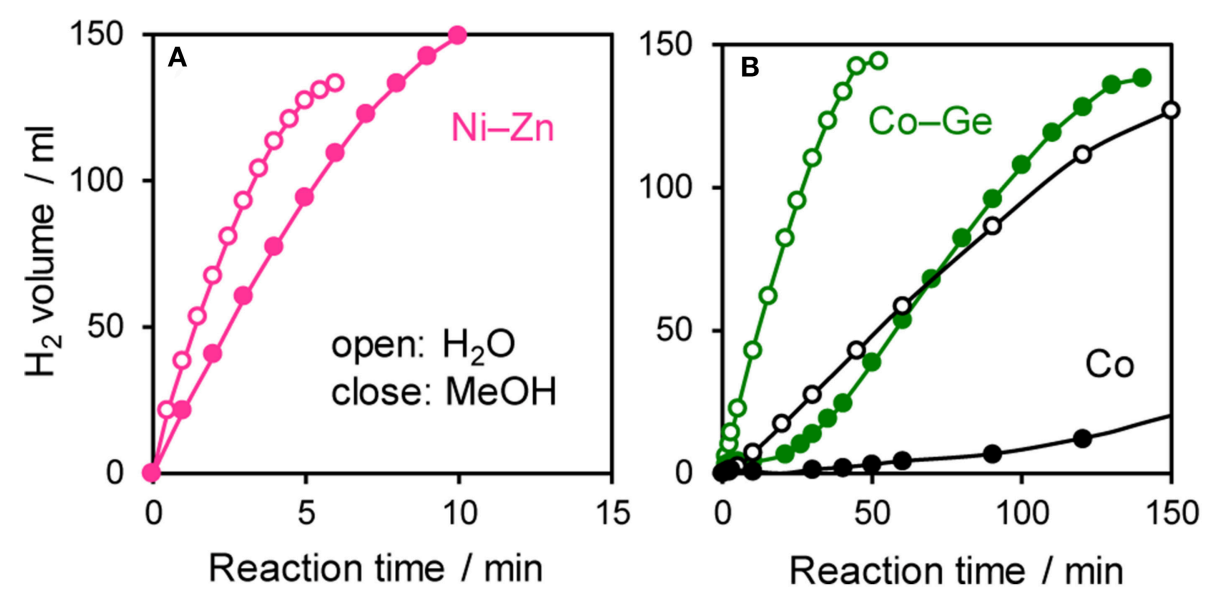

FIGURE 2 | Time course of $\mathrm{H}_{2}$ evolution during catalytic hydrolysis $\left(\mathrm{H}_{2} \mathrm{O}\right)$ and methanolysis $(\mathrm{MeOH})$ of $\mathrm{AB}$ using $\mathbf{( A )} \mathrm{Ni}-\mathrm{Zn}$, (B) Co-Ge, and Co catalyst. 
grove box $\left(\mathrm{O}_{2}\right.$ concentration: $\left.<1 \mathrm{ppm}\right)$ and then introduced into the spectrometer without exposure to air. Spectra were obtained with an $\mathrm{Al} \mathrm{K \alpha} \mathrm{X}$-ray source, using $\mathrm{C} 1$ s as a reference for binding energy $(284.8 \mathrm{eV})$. The reduction behavior of the catalyst was examined by temperature-programmed reduction (TPR). Under flowing $\mathrm{H}_{2}(5 \%) / \mathrm{Ar}$, the temperature of the sample bed was raised from room temperature to $900^{\circ} \mathrm{C}$ at a heating rate of $10^{\circ} \mathrm{C} \cdot \mathrm{min}^{-1}$ and the consumption of hydrogen was continuously measured by a thermal conductivity detector (TCD).

\section{Catalytic Reaction}

A catalyst $(100 \mathrm{mg})$ was placed into a $50 \mathrm{~mL}$ three-necked roundbottom flask equipped with a silicone rubber septum and a gas burette and pretreated under an $\mathrm{H}_{2}$ stream $\left(60 \mathrm{~mL} \cdot \mathrm{min}^{-1}\right)$ at $450^{\circ} \mathrm{C}$ for $0.5 \mathrm{~h}$ using a mantle heater. After the pretreatment, dry $\operatorname{Ar}\left(20 \mathrm{~mL} \cdot \mathrm{min}^{-1}\right)$ was passed into the flask to replace the residual $\mathrm{H}_{2}$, and the flask was cooled to room temperature. A reaction mixture containing a solvent (deionized water or dehydrated methanol, Kanto 99.8\%, $10 \mathrm{~mL}$ ) and AB (Sigma-Aldrich, 97\%, 2.0 $\mathrm{mmol}$ ) was added into the flask through the septum at $25^{\circ} \mathrm{C}$. The volume of the evolved $\mathrm{H}_{2}$ was measured using the gas burette. The total volume of $\mathrm{H}_{2}$ is expected to be $147 \mathrm{ml}(6.0 \mathrm{mmol})$ at $25^{\circ} \mathrm{C}$ for the complete conversion of $\mathrm{AB}(2.0 \mathrm{mmol})$.

\section{RESULTS AND DISCUSSION}

The prepared $\mathrm{Ni}$ - and Co-based catalysts were tested for $\mathrm{H}_{2}$ production from $\mathrm{AB}$ using methanol as a solvent (Figure 1). The monometallic Ni catalyst showed moderate catalytic activity with a short induction period. The Ni-Sn catalyst showed a very low catalytic activity with a long induction period. On the other hand, the Ni-Zn, Ni-Ga, and Ni-Ge catalysts exhibited high catalytic activities without an induction period. Particularly for the $\mathrm{Ni}-$ $\mathrm{Zn}$ catalyst, the reaction was completed within ca. $10 \mathrm{~min}$. Cobased catalysts generally gave catalytic activities lower than those of Ni-based catalysts, which reflects the intrinsic difference of catalytic activity between $\mathrm{Ni}$ and $\mathrm{Co}$ for this reaction. Moreover, the catalytic activities were quite different depending on the second metal ( $\mathrm{Co}-\mathrm{Ge}>\mathrm{Co}-\mathrm{Ga}>>\mathrm{Co}>>\mathrm{Co}-\mathrm{Sn})$. Induction periods were observed for some catalysts $(\mathrm{Ni}, \mathrm{Ni}-\mathrm{Sn}, \mathrm{Co}, \mathrm{Co}-$ $\mathrm{Ga}$, and $\mathrm{Co}-\mathrm{Zn}$ ), indicating that, for these catalysts, some real active species (probably, zero-valent $\mathrm{Ni}$ or Co species) were formed or increased during the catalytic reaction. A remarkable

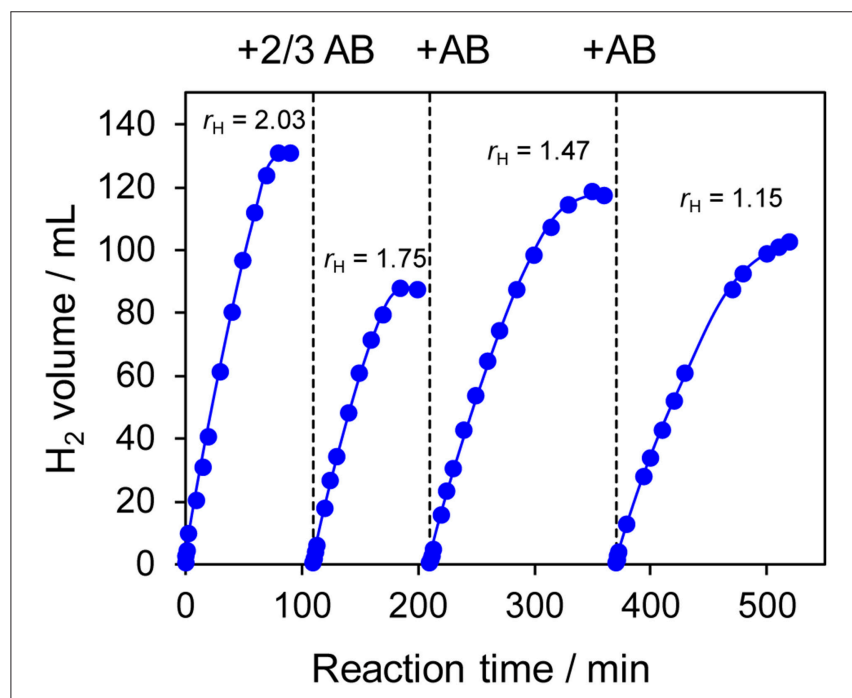

FIGURE 3 | Reuse tests for $\mathrm{H}_{2}$ production in methanol using $\mathrm{Co}-\mathrm{Ge} / \mathrm{SiO}_{2}$ catalyst. For the first reuse at $110 \mathrm{~min}$, the amount of $A B$ was reduced to $2 / 3$ (1.33 mmol).

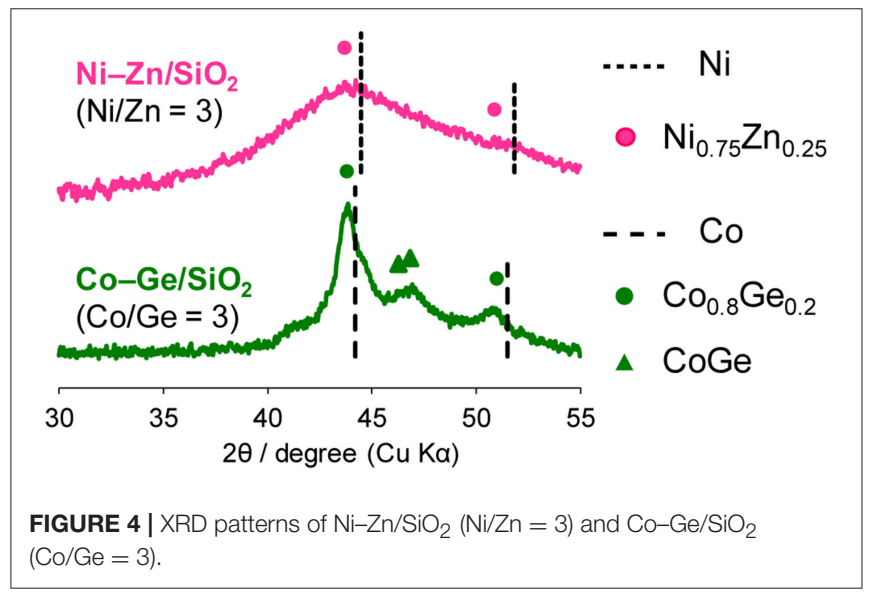

TABLE 1 | Summary of reaction condition and rate of $A B$ hydrolysis at $25^{\circ} \mathrm{C}$ using various catalysts.

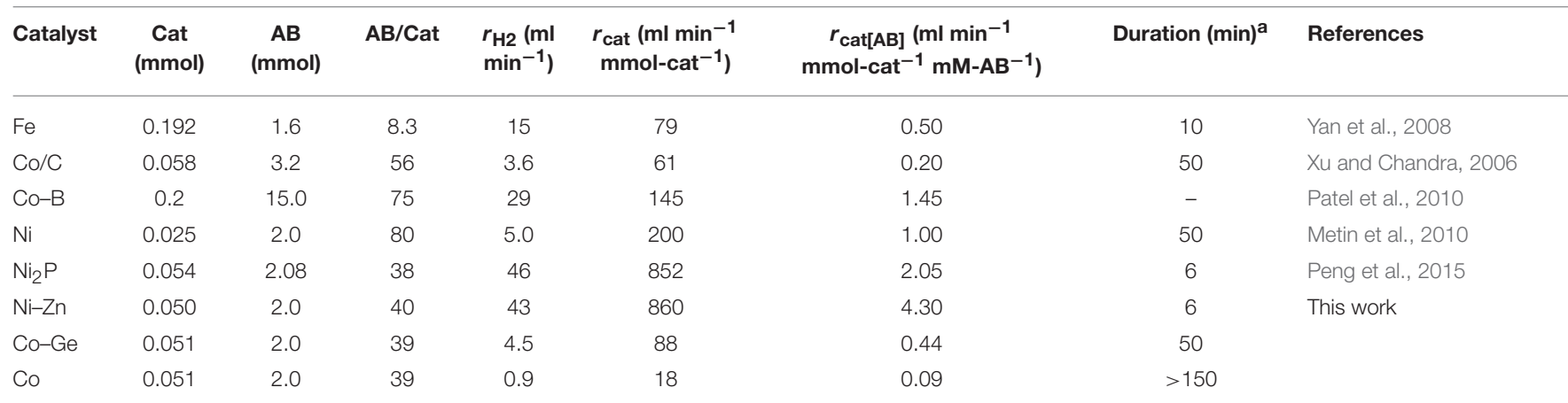

a Time needed for completion of $\mathrm{H}_{2}$ evolution. 
enhancement in the reaction rate was achieved by addition of $\mathrm{Ge}$ to Co, suggesting the contribution of a specific effect of $\mathrm{Ge}$ on the catalysis. The discovered active catalysts, $\mathrm{Ni}-\mathrm{Zn}$ and $\mathrm{Co}-\mathrm{Ge}$, were also tested in hydrogen production from $\mathrm{AB}$ in water as a solvent (Figure 2). For each catalyst, $\mathrm{H}_{2}$ evolution in water was much faster than that in methanol as reported for $\mathrm{Ni}$ - and Co-based catalysts in the literature. Note that the reaction was completed within $6 \mathrm{~min}$ when the $\mathrm{Ni}-\mathrm{Zn}$ catalyst was used. This is one of the best performances in $A B$ hydrolysis reported to this day. The obtained catalytic performance was listed in Table 1 with those of reported catalysts. Because the reaction conditions were different depending on each study, we quantitatively compared them based on the specific $\mathrm{H}_{2}$ formation rates $\left(r_{\mathrm{cat}[\mathrm{AB}]}\right)$ calculated by dividing $\mathrm{H}_{2}$ formation rates $\left(r_{\mathrm{H} 2}\right)$ by the amount of catalyst ( $\mathrm{mmol}$ ) and concentration of $\mathrm{AB}$ $(\mathrm{mM})$. Since the number of active sites, such as metal atoms on the surface, was not clearly mentioned, the total number of metal atoms was used for this calculation. The difference in $\mathrm{AB}$ concentration was compensated for by assuming the firstorder dependence of the formation rate on $\mathrm{AB}$ concentration. The Ni-Zn catalyst exhibited an $r_{\text {cat }[\mathrm{AB}]}$ value higher than that of $\mathrm{Ni}_{2} \mathrm{P}$, which was reported to be the most active base-metal catalyst for AB hydrolysis (Peng et al., 2015). Therefore, the Ni$\mathrm{Zn}$ catalyst is the most active $3 \mathrm{~d}$ metal-based catalyst for $\mathrm{H}_{2}$ production by hydrolysis of $\mathrm{AB}$. We also examined the reusability of the catalysts. Figure 3 shows the result of the reuse test for

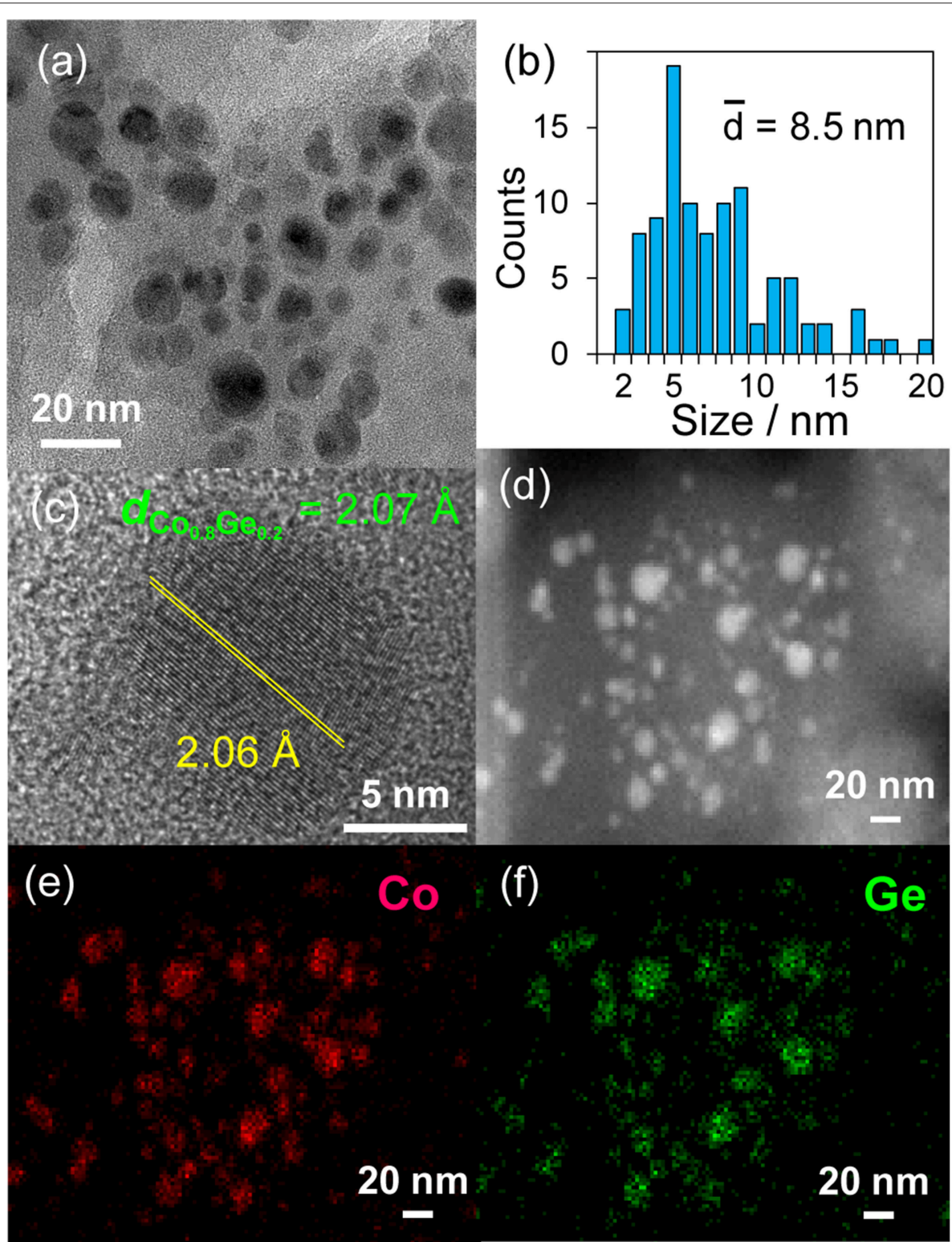

FIGURE 5 | (a) TEM image and the (b) size distribution of $\mathrm{Co}-\mathrm{Ge} / \mathrm{SiO}_{2}$ catalyst. (c) High resolution TEM image of a single nanoparticle of Co-Ge. (d) HAAF-STEM image of $\mathrm{Co}-\mathrm{Ge} / \mathrm{SiO}_{2}$ catalyst and elemental maps of (e) $\mathrm{Co}$, and (f) $\mathrm{Ge}$ for the nanoparticles acquired using EDS. 
the $\mathrm{Co}-\mathrm{Ge} / \mathrm{SiO}_{2}$ catalyst in $\mathrm{H}_{2}$ production in methanol. At the first reuse at $110 \mathrm{~min}$, we added $1.33 \mathrm{~mol}$ of $\mathrm{AB}$ (2/3 equivalent to the standard condition). The total volume $\mathrm{H}_{2}$ evolved decreased from 130.5 to $87 \mathrm{ml}$, showing complete conversion of $\mathrm{AB}$ at reuse. The reaction rate also became approximately two-thirds of the original (2.03-1.75), indicating that $r_{\mathrm{H} 2}$ strongly depends on $\mathrm{AB}$ concentration. Although the reaction rate was slightly decreased at the second and third reuse, the $\mathrm{Co}-\mathrm{Ge} / \mathrm{SiO}_{2}$ catalyst could be reused without any regeneration procedure. Thus, it was found that the $\mathrm{Co}-\mathrm{Ge} / \mathrm{SiO}_{2}$ was a recyclable heterogeneous catalyst for $\mathrm{H}_{2}$ production from $\mathrm{AB}$.

Then, the discovered active catalysts were characterized to clarify their structures. Figure 4 shows XRD patterns of the $\mathrm{Ni}-\mathrm{Zn} / \mathrm{SiO}_{2}$ and $\mathrm{Co}-\mathrm{Ge} / \mathrm{SiO}_{2}$ catalysts. For $\mathrm{Ni}-\mathrm{Zn} / \mathrm{SiO}_{2}$, a solid-solution alloy between $\mathrm{Ni}$ and $\mathrm{Zn}$ with a 3: 1 ratio, namely $\mathrm{Ni}_{0.75} \mathrm{Zn}_{0.25}$ phase (Vassilev, 1992), was observed as single phase. A similar alloy phase $\left(\mathrm{Co}_{0.8} \mathrm{Ge}_{0.2}\right)$ (Ishida and Nishizawa, 1991) was also observed as a main species for $\mathrm{Co}-\mathrm{Ge} / \mathrm{SiO}_{2}$. One-to-one intermetallic phase of CoGe was also detected as a minor species. Thus, XRD analysis confirmed the formation of alloy phases with high purities. The crystallite sizes of $\mathrm{Ni}-\mathrm{Zn}$ and $\mathrm{Co}-\mathrm{Ge}$ were estimated using Scherrer equation as $<3$ and $9 \mathrm{~nm}$, respectively. The larger crystallite size of $\mathrm{Co}-\mathrm{Ge}$ may stem from the higher reduction temperature $\left(800^{\circ} \mathrm{C}\right)$ during the catalyst preparation. Figure 5 shows TEM and STEM images of $\mathrm{Co}-\mathrm{Ge} / \mathrm{SiO}_{2}$, size distribution of nanoparticles, and the elemental map of $\mathrm{Co}$ and Ge acquired using EDS. Particle size ranged from 2 to $20 \mathrm{~nm}$ with a mean diameter of $8.5 \mathrm{~nm}$ (Figures 5a,b), which is consistent with the crystallite size estimated by the Scherrer equation $(9 \mathrm{~nm})$. Figure $5 \mathrm{c}$ displays the high-resolution TEM image of a single Co-Ge nanoparticle. Lattice fringes with $2.06 \AA$ spacing were clearly observed, which agrees finely with the interplanar distance of the (111) plane of $\mathrm{Co}_{0.8} \mathrm{Ge}_{0.2}$ solid-solution alloy with an fcc structure (2.07 $\AA$ ) (Ishida and Nishizawa, 1991). The elemental maps of Co and Ge that were acquired using the EDS analysis revealed that the $\mathrm{Co}$ and $\mathrm{Ge}$ atoms comprising the nanoparticles were homogeneously dispersed (Figures $\mathbf{5 d - f}$ ). These results strongly suggest that the $\mathrm{Co}_{0.8} \mathrm{Ge}_{0.2}$ alloy nanoparticles were formed with high phase purities. Thus, the results obtained from the STEM-EDS analysis were consistent with that of XRD.

We then studied the reason why the catalytic activity was significantly enhanced by the formation of the alloy phase. Because the Co-Ge system exhibited a remarkable increase in the reaction rate (five times higher) compared to pure $\mathrm{Co}$, we focused on the difference between the Co and Co-Ge systems.

Figure 6 shows the TPR profiles of the $\mathrm{Co} / \mathrm{SiO}_{2}$ and $\mathrm{Co}-$ $\mathrm{Ge} / \mathrm{SiO}_{2}$ catalysts. To evaluate the reduction temperatures of the component metals, as-impregnated catalysts were used for the TPR experiments. For both catalysts, intense peaks were observed at 150 and $200^{\circ} \mathrm{C}$, which may be attributed to the reduction of $\mathrm{O}_{2}$ or $\mathrm{NO}_{2}$ derived from the decomposition of the $\mathrm{Co}\left(\mathrm{NO}_{3}\right)_{2}$ (van Steen et al., 1996). For $\mathrm{Co} / \mathrm{SiO}_{2}$, two reduction peaks were observed at 260 and $760^{\circ} \mathrm{C}$, which are assigned to the reduction of $\mathrm{Co}^{2+}$ species that weakly and strongly interact with the silica surface, respectively (van Steen et al., 1996). On the contrary, for
$\mathrm{Co}-\mathrm{Ge} / \mathrm{SiO}_{2}$, three different reduction peaks were observed at 370,550 , and $740^{\circ} \mathrm{C}$, which could be assigned to the reduction of $\mathrm{Co}^{2+}, \mathrm{Co}^{3+}$, and $\mathrm{Ge}^{4+}$ species. We previously reported a TPR profile of $\mathrm{Ge} / \mathrm{SiO}_{2}$, with reduction peaks appearing at temperatures higher than $650^{\circ} \mathrm{C}$ (Komatsu et al., 1997). Therefore, the reduction peak at $740^{\circ} \mathrm{C}$ can be attributed to the reduction of $\mathrm{Ge}^{4+}$. The other reduction peaks assignable for Co species appeared at much higher temperatures than that for $\mathrm{Co} / \mathrm{SiO}_{2}$, suggesting that the strong interaction between $\mathrm{Co}$ and $\mathrm{Ge}$ inhibits the reduction of $\mathrm{Co}^{2+}$. It can be said that $\mathrm{Co}$ species in $\mathrm{Co} / \mathrm{SiO}_{2}$ were not completely reduced because the reduction temperature for the preparation of $\mathrm{Co} / \mathrm{SiO}_{2}\left(600^{\circ} \mathrm{C}\right)$ is not sufficient to completely reduce all the Co species. This

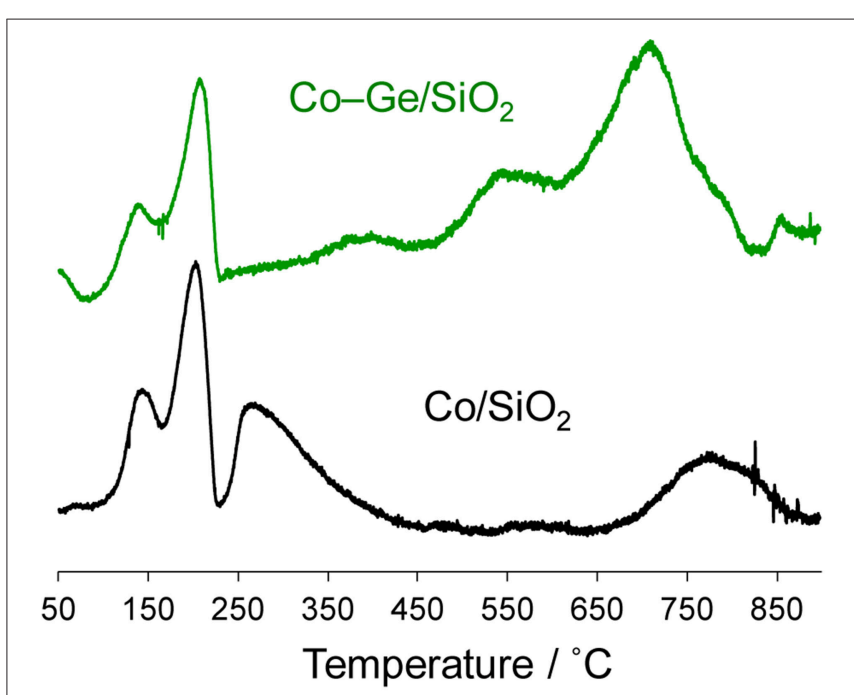

FIGURE 6 | TPR profiles for as-impregnated $\mathrm{Co}\left(\mathrm{NO}_{3}\right)_{2} / \mathrm{SiO}_{2}$ and $\mathrm{Co}\left(\mathrm{NO}_{3}\right)_{2}-\left(\mathrm{NH}_{4}\right)_{2} \mathrm{GeF}_{6} / \mathrm{SiO}_{2}$ catalysts.

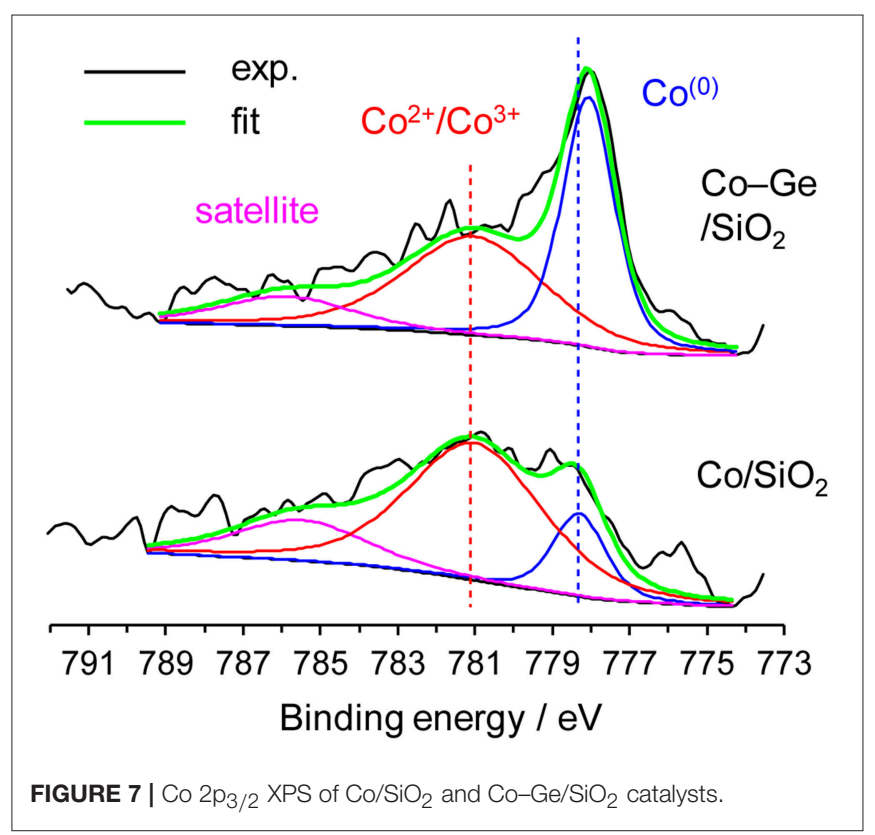


may be one of the reasons why the $\mathrm{Co} / \mathrm{SiO}_{2}$ catalysts showed low catalytic activity. On the contrary, for $\mathrm{Co}-\mathrm{Ge} / \mathrm{SiO}_{2}$, the reduction temperature for the preparation $\left(800^{\circ} \mathrm{C}\right)$ is enough to reduce all the $\mathrm{Co}^{2+}$ and $\mathrm{Ge}^{4+}$ species.

We also investigated the electronic states of the $\mathrm{Co} / \mathrm{SiO}_{2}$ and $\mathrm{Co}-\mathrm{Ge} / \mathrm{SiO}_{2}$ catalysts by XPS (Figure 7). For $\mathrm{Co} / \mathrm{SiO}_{2}$, the fraction of $\mathrm{Co}^{2+}$ or $\mathrm{Co}^{3+}$ species (Sexton et al., 1986) was much higher than that of $\mathrm{Co}^{(0)}$, suggesting that a large part of the catalyst surface is oxidized. By contrast, for $\mathrm{Co}-\mathrm{Ge} / \mathrm{SiO}_{2}, \mathrm{Co}^{(0)}$ (Sexton et al., 1986) was detected as a main species. These results are consistent with the expectation derived from TPR mentioned above. It is also likely that $\mathrm{Co}$ atoms on the $\mathrm{Co}-\mathrm{Ge} / \mathrm{SiO}_{2}$ catalyst are more resistant to aerobic oxidation than those on $\mathrm{Co} / \mathrm{SiO}_{2}$. Jagirdar et al. reported that $\mathrm{Co}^{2+}$ or $\mathrm{Ni}^{2+}$ ions could be reduced by the evolved $\mathrm{H}_{2}$ during hydrolysis of $\mathrm{AB}$ to form $\mathrm{Ni}$ or $\mathrm{Co}$ nanoparticles (Kalidindi et al., 2008). Therefore, it is likely that similar in situ reduction of $\mathrm{Co}^{2+}$ could occur to completely reduce the catalyst surface in our system. This may be the reason why the induction period was observed in $\mathrm{H}_{2}$ production from $\mathrm{AB}$ over $\mathrm{Co} / \mathrm{SiO}_{2}$. The binding energies of $\mathrm{Co}^{2+}$ or $\mathrm{Co}^{3+}$ for $\mathrm{Co} / \mathrm{SiO}_{2}$ and $\mathrm{Co}-\mathrm{Ge} / \mathrm{SiO}_{2}$ were almost same, suggesting that $\mathrm{Ge}$ species do not affect the electronic state of Co cations. However, a different trend was observed for $\mathrm{Co}^{(0)}$ species: $\mathrm{Co}-\mathrm{Ge} / \mathrm{SiO}_{2}$ exhibited a lower binding energy than $\mathrm{Co} / \mathrm{SiO}_{2}$, indicating that $\mathrm{Co}$ atoms in $\mathrm{Co}-\mathrm{Ge}$ are electron-enriched compared with pure Co. This is probably because electron transfer from Ge to Cooccurs due to alloy formation. Similar electron transfer has also been reported for the relevant systems such as Pt-Ge alloys (Komatsu et al., 1997). Thus, XPS analysis revealed that the formation of $\mathrm{Co}-\mathrm{Ge}$ alloy drastically changed the electronic state of Co. On the basis of these results, we considered that the difference in the electron density of $\mathrm{Co}^{(0)}$ species, namely, electron-enrich Co by Ge via alloying, is the key factor for the remarkable enhancement in the catalytic activity.

The reaction mechanism of $\mathrm{AB}$ hydrolysis has been reported as follows: (1) the formation of an activated complex between $\mathrm{AB}$ and the metal surface, (2) B-N bond scission assisted by $\mathrm{H}_{2} \mathrm{O}$ attack, and (3) hydrolysis of the resulting $\mathrm{BH}_{3}$ moiety to form $\mathrm{H}_{2}$ and $\mathrm{BO}_{2}^{-}$(Xu and Chandra, 2006; Mahyari and Shaabani, 2014). It is also known that $\mathrm{H}$ atoms bound to the $\mathrm{B}$ and $\mathrm{N}$ atoms are slightly electropositive and electronegative,

\section{REFERENCES}

Chandra, M., and Xu, Q. (2007). Room temperature hydrogen generation from aqueous ammonia-borane using noble metal nano-clusters as highly active catalysts. J. Power Sources 168, 135-142. doi: 10.1016/j.jpowsour.2007.03.015

Chen, S. S., Takata, T., and Domen, K. (2017). Particulate photocatalysts for overall water splitting. Nat. Rev. Mater. 2:17050. doi: 10.1038/Natrevmats.2017.50

Furukawa, S., and Komatsu, T. (2017). Intermetallic compounds: promising inorganic materials for well-structured and electronically modified reaction environments for efficient catalysis. ACS Catalysis 7, 735-765. doi: 10.1021/acscatal.6b02603

Han, J., Zheng, X., Zhang, L., Fu, H., and Chen, J. (2017). Removal of $\mathrm{SO}_{2}$ on a nanoporous photoelectrode with simultaneous $\mathrm{H}_{2}$ production. Environ. Sci. Nano 4, 834-842. doi: 10.1039/C6EN00638H respectively, due to the different electronegativities of $\mathrm{B}$ and $\mathrm{N}$. Therefore, it is likely that the alloy surface with polar active sites $\left(\mathrm{Co}^{\delta-}-\mathrm{Ge}^{\delta+}\right)$ facilitates the formation of the active complex (1), thus enhancing the following steps and the overall reaction rate. A similar reaction mechanism has also been reported in the system of $\mathrm{Ru}^{\delta-}-\mathrm{Ni}^{\delta+}$ bimetallic catalysts for $\mathrm{AB}$ hydrolysis (Mori et al., 2016).

\section{CONCLUSION}

In this study, we prepared a series of $\mathrm{Ni}$ - and Co-based bimetallic catalysts $\left(\mathrm{Ni}-\mathrm{M} / \mathrm{SiO}_{2}\right.$ and $\mathrm{Co}-\mathrm{M} / \mathrm{SiO}_{2} ; \mathrm{M}=\mathrm{Ga}$, $\mathrm{Ge}, \mathrm{Sn}$, and $\mathrm{Zn}$ ) and tested them in $\mathrm{H}_{2}$ production from $\mathrm{AB}$ in water or methanol. Catalytic activity for hydrogen production is enhanced by the addition of second metals except Sn. Particularly, the addition of Ge to Co enables great enhancement in the catalytic activity, namely a fivefold higher $r_{\mathrm{H} 2}$ than the monometallic $\mathrm{Co} / \mathrm{SiO}_{2}$ catalyst. The active species is electron-enriched Co atoms constituting the $\mathrm{Co}_{0.8} \mathrm{Ge}_{0.2}$ solid solution alloy phase. The $\mathrm{Ni}-\mathrm{Zn} / \mathrm{SiO}_{2}$ catalyst exhibited an $r_{\text {cat }[\mathrm{AB}]}$ value higher than those ever reported for hydrolysis of $\mathrm{AB}$ to the best of our knowledge. The $\mathrm{Ni}_{0.75} \mathrm{Zn}_{0.25}$ solid solution alloy phase acts as the active species.

\section{AUTHOR CONTRIBUTIONS}

SF designed the research and experiments. GN performed all the experiments. TT managed the HAADF-STEM-EDS analysis. SF and TK prepared the manuscript.

\section{FUNDING}

This work was supported by JSPS KAKENHI grant numbers 26820350 and $17 \mathrm{H} 0496508$.

\section{ACKNOWLEDGMENTS}

We deeply appreciate the Center for Advanced Materials Analysis of the Tokyo Institute of Technology for the aid of TEM and STEM observation.
Heinzel, A., Vogel, B., and Hübner, P. (2002). Reforming of natural gas-hydrogen generation for small scale stationary fuel cell systems. J. Power Sources 105, 202-207. doi: 10.1016/S0378-7753(01)00940-5

Ishida, K., and Nishizawa, T. (1991). The Co-Ge (cobalt-germanium) system. J. Phase Equilibria 12, 77-83. doi: 10.1007/BF02 663679

Kalidindi, S. B., Indirani, M., and Jagirdar, B. R. (2008). First row transition metal ion-assisted ammonia-borane hydrolysis for hydrogen generation. Inorgan. Chem. 47, 7424-7429. doi: 10.1021/ic8 $00805 \mathrm{r}$

Kalidindi, S. B., Vernekar, A. A., and Jagirdar, B. R. (2009). Co-Co2B, $\mathrm{Ni}-\mathrm{Ni} 3 \mathrm{~B}$ and $\mathrm{Co}-\mathrm{Ni}-\mathrm{B}$ nanocomposites catalyzed ammonia-borane methanolysis for hydrogen generation. Phys. Chem. Chem. Phys. 11, 770-775. doi: $10.1039 / \mathrm{b} 814216 \mathrm{e}$ 
Komatsu, T., Hyodo, S., and Yashima, T. (1997). Catalytic properties of Pt-Ge intermetallic compounds in the hydrogenation of 1,3-butadiene. J. Phys. Chem. B 101, 5565-5572. doi: 10.1021/Jp9711171

Landge, V. G., Pitchaimani, J., Midya, S. P., Subaramanian, M., Madhu, V., and Balaraman, E. (2018). Phosphine-free cobalt pincer complex catalyzed Zselective semi-hydrogenation of unbiased alkynes. Catalysis Sci. Technol. 8, 428-433. doi: 10.1039/c7cy01994g

Mahyari, M., and Shaabani, A. (2014). Nickel nanoparticles immobilized on threedimensional nitrogen-doped graphene as a superb catalyst for the generation of hydrogen from the hydrolysis of ammonia borane. J. Mater. Chem. A 2, 16652-16659. doi: 10.1039/c4ta03940h

Marder, T. B. (2007). Will we soon be fueling our automobiles with ammoniaborane? Angew. Chem. Int. Ed. 46, 8116-8118. doi: 10.1002/anie.2007 03150

Metin, O., Mazumder, V., Ozkar, S., and Sun, S. S. (2010). Monodisperse nickel nanoparticles; and their catalysis in hydrolytic dehydrogenation of ammonia borane. J. Am. Chem. Soc. 132, 1468-1469. doi: 10.1021/ja909243z

Moniz, S. J. A., Shevlin, S. A., Martin, D. J., Guo, Z. X., and Tang, J. W. (2015). Visible-light driven heterojunction photocatalysts for water splitting - a critical review. Energy Environ. Sci. 8, 731-759. doi: 10.1039/c4ee03271c

Mori, K., Miyawaki, K., and Yamashita, H. (2016). Ru and Ru-Ni nanoparticles on $\mathrm{TiO}_{2}$ support as extremely active catalysts for hydrogen production from ammonia-borane. ACS Catalysis 6, 3128-3135. doi: 10.1021/acscatal. $6 \mathrm{~b} 00715$

Ozay, O., Inger, E., Aktas, N., and Sahiner, N. (2011). Hydrogen production from ammonia borane via hydrogel template synthesized $\mathrm{Cu}, \mathrm{Ni}$, Co composites. Int. J. Hydrogen Energy 36, 8209-8216. doi: 10.1016/j.ijhydene.2011. 04.140

Patel, N., Fernandes, R., Guella, G., and Miotello, A. (2010). Nanoparticleassembled Co-B thin film for the hydrolysis of ammonia borane: a highly active catalyst for hydrogen production. Appl. Catalysis B Environ. 95, 137-143. doi: 10.1016/j.apcatb.2009.12.020

Peng, C. Y., Kang, L., Cao, S., Chen, Y., Lin, Z. S., and Fu, W. F. (2015). Nanostructured $\mathrm{Ni}_{2} \mathrm{P}$ as a robust catalyst for the hydrolytic dehydrogenation of ammonia-borane. Angew. Chem. Int. Ed. 54, 15725-15729. doi: 10.1002/anie.201508113

Schlapbach, L., and Züttel, A. (2011). "Hydrogen-storage materials for mobile applications," in Materials for Sustainable Energy: A Collection of Peer-Reviewed Research and Review Articles from Nature Publishing Group, ed V. Dusastre (London: World Scientific), 265-270.

Sexton, B., Hughes, A., and Turney, T. (1986). An XPS and TPR study of the reduction of promoted cobalt-kieselguhr Fischer-Tropsch catalysts. J. Catalysis 97, 390-406. doi: 10.1016/0021-9517(86)90011-4 van Steen, E., Sewell, G. S., Makhothe, R. A., Micklethwaite, C., Manstein, H., de Lange, M., et al. (1996). TPR study on the preparation of impregnated $\mathrm{Co} / \mathrm{SiO}_{2}$ catalysts. J. Catalysis 162, 220-229. doi: 10.1006/jcat.1996.0279

Vassilev, G. P. (1992). Thermodynamic evaluation of the Ni-Zn system. J. Alloys Compounds 190, 107-112. doi: 10.1016/0925-8388(92)90184-B

Wang, Q., Hisatomi, T., Suzuk, Y., Pan, Z. H., Seo, J., Katayama, M., et al. (2017). Particulate photocatalyst sheets based on carbon conductor layer for efficient Z-scheme pure-water splitting at ambient pressure. J. Am. Chem. Soc. 139, 1675-1683. doi: 10.1021/jacs.6b12164

$\mathrm{Xu}$, Q., and Chandra, M. (2006). Catalytic activities of non-noble metals for hydrogen generation from aqueous ammonia-borane at room temperature. $J$. Power Sources 163, 364-370. doi: 10.1016/j.jpowsour.2006.09.043

$\mathrm{Xu}, \mathrm{Q}$., and Chandra, M. (2007). A portable hydrogen generation system: catalytic hydrolysis of ammonia-borane. J. Alloys Compounds 446, 729-732. doi: 10.1016/j.jallcom.2007.01.040

Yan, J. M., Zhang, X. B., Han, S., Shioyama, H., and Xu, Q. (2008). Iron-nanoparticle-catalyzed hydrolytic dehydrogenation of ammonia borane for chemical hydrogen storage. Angew. Chem. Int. Ed. 47, 2287-2289. doi: 10.1002/anie.200704943

Yan, J. M., Zhang, X. B., Han, S., Shioyama, H., and Xu, Q. (2009). Synthesis of longtime water/air-stable ni nanoparticles and their high catalytic activity for hydrolysis of ammonia-borane for hydrogen generation. Inorgan. Chem. 48, 7389-7393. doi: 10.1021/ic900921m

Zhang, L., Reisner, E., and Baumberg, J. J. (2014). Al-doped $\mathrm{ZnO}$ inverse opal networks as efficient electron collectors in $\mathrm{BiVO}_{4}$ photoanodes for solar water oxidation. Energy Environ. Sci. 7, 1402-1408. doi: 10.1039/C3EE 44031A

Zheng, X. Z., and Zhang, L. W. (2016). Photonic nanostructures for solar energy conversion. Energy Environ. Sci. 9, 2511-2532. doi: 10.1039/c6ee01182a

Züttel, A. (2003). Materials for hydrogen storage. Mater. Today 6, 24-33. doi: 10.1016/S1369-7021(03)00922-2

Conflict of Interest Statement: The authors declare that the research was conducted in the absence of any commercial or financial relationships that could be construed as a potential conflict of interest.

Copyright ( 2019 Furukawa, Nishimura, Takayama and Komatsu. This is an openaccess article distributed under the terms of the Creative Commons Attribution License (CC BY). The use, distribution or reproduction in other forums is permitted, provided the original author(s) and the copyright owner(s) are credited and that the original publication in this journal is cited, in accordance with accepted academic practice. No use, distribution or reproduction is permitted which does not comply with these terms. 